Journal of Economics and Behavioral Studies

Vol. 6, No. 3, pp. 181-187, Mar 2014 (ISSN: 2220-6140)

\title{
The Association between the Socioeconomic Status and the Magnitude of HIV/AIDS in Kinshasa
}

\author{
Christian Ayikwa, *Johan W De Jager, Ben J van Rensburg \\ Tshwane University of Technology, South Africa \\ *DeJagerJW@tut.ac.za
}

\begin{abstract}
Researches devoted to the HIV/AIDS issue divide the scientific community between the supporters of an association socioeconomic status-HIV/AIDS and those estimating that there is no pattern between them. Studies conducted across the world's most affected regions assert one another opinion on the basis of findings scientifically proven. In addition, some other studies argue that the link poverty-HIV/AIDS is vicious, meaning that poverty cause HIV/AIDS and vice versa. The present study conducted in Kinshasa, one of the African cities characterised by a certain level of poverty, aims at investing the potential correlation socioeconomic status and magnitude of HIV/AIDS in its specific context as well as contributes to the debate that took place in the scientific community between both mainstreams evoked previously. Although the study found no relationship between people socioeconomic status and either their sexual behaviour, HIV/AIDS knowledge (3 variables), accessibility to information or availability of condoms, as well as no statistically significant difference between socio economic groups in these mentioned variables, it estimates that it is all matter of space and time rather than pronouncing a judgement about who is right or wrong. Therefore no one is wrong, all are right.
\end{abstract}

Keywords: HIV/AIDS, Socioeconomic status, Poverty, Kinshasa, Level of knowledge, Sexual behaviour, attitude, Information and Condoms

\section{Introduction}

For more than half a century, HIV/AIDS prevention campaigns are conducted across the continent to alleviate the spread of the disease, yet the pandemic remains a serious threat to Africa's development as it continues to gain ground, hence necessitating more efforts and researches. Authors in the field of social marketing have observed that HIV/AIDS flourishes in an environment characterised by poverty that makes people vulnerable, especially girls and young women (Booysen \& Summerton, 2002:285). Thus, a variety of studies conducted across the most HIV/AIDS affected region in the world (Specially Africa and Asia) found that the socioeconomic status is one of the sociodemographic factors, and not the less, associated with HIV/AIDS infection in the general population (Slaymaker et al., 2004:1197). Authors such as Meekers and Rahaim (2005) argued that the impact and effectiveness of social marketing models depend on their adaptation to the socio-economic context within which they are applied. As it is convincingly proven that HIV/AIDS is correlated with poverty (Bärnighausen et al., 2007:S29), people socioeconomic status might be considered as a determinant of their behaviour towards their sexual practices and condom use (Mabala, 2006; Price, 2001).

\section{Literature Review}

HIV/AIDS has become the terrain of moralists that insist on the fact that individual behaviour drives the pandemic, regardless of the obvious truth that HIV/AIDS flourishes in a situation of poverty, compounded by inequity and lack of social cohesion, and that those most affected by it are precisely those who are affected by that actual environment. For Mabala (2006:407), HIV/AIDS prevention methodologies need to be revisited, especially in urban areas. As with other epidemics, both physical and social environment play a key role in the spreading of the virus - "The microbe is nothing, the terrain everything." (Louis Pasteur cited by Mabala, 2006:407). Hence, ignoring crucial structural and environmental factors influencing an individual's behaviour such as socioeconomic status in implementing HIV/AIDS strategies highlights the inadequacy of current behaviour change interventions, quite apart from the fact that the most vulnerable are not even reached by these interventions (Price, 2001). However, the entire scientific community does not come to an agreement 
on who drives who between socioeconomic status and HIV/AIDS. Barnett and Whiteside (2002) demonstrate the vicious link between HIV/AIDS and poverty, asserting the existence of an undoubted relationship between poverty and the development of the epidemics of communicable disease. The same epidemic disease - like any illness - has the potential to increase poverty. Repeatedly, poverty has been referred to as an element that influences the spread of HIV/AIDS rather than wealthy which is often omitted. A study conducted in Manicaland in Zimbabwe has arrived at a conclusion that the impact of the virus and its related mortality, and perhaps unsafe sexual behaviour, are lower in higher socioeconomic groups (Lopman et al., 2007:S57). Thus, HIV/AIDS is presented simply as a 'disease of poverty' (Gillespie et al., 2007a). However though poor individuals seems likely to be hit harder by the downstream impacts of the pandemic than their less poor counterparts, there is no evidence that they are most-at-risk of infection than wealthier individuals (Gillespie et al., 2007b). According to Mishra et al. (2007:S17), the association between poverty and HIV/AIDS prevalence does not exhibit the same pattern like in most other diseases including nutrition, morbidity and mortality, and healthcare utilisation. Therefore, HIV/AIDS prevention programmes should also focus on the wealthier segments of the population. However, earlier in 2001, Price has instead blamed HIV/AIDS interventions to be likely devoted to service the wealthier than their poorer counterparts. Hence, it becomes imperious to find out if there is any form of discrimination from HIV/AIDS prevention interventions in providing all socioeconomic groups with HIV/AIDS knowledge, information and condoms.

The Democratic Republic of Congo, one of the pioneers of African countries to diagnose HIV/AIDS only two years after the first ever case in the United States, registered its first case in 1983 (Khonde, 2006:219). After over three decades, HIV/AIDS estimates indicated, end of 2003, 1.1 million people living with the virus while the number of death related to the pandemic stand at 100 thousands, and the current living orphan at 770 thousands (UNAIS/WHO, 2004:2). The percentage of HIV infected people receiving antiretroviral treatment was estimated at $8.6 \%$. The adult prevalence rate was estimated at $3.2 \%$ country wide while Kinshasa itself recorded an alarming $22.2 \%$ prevalence rate in most-at-risk populations (USAID, 2008). These numbers reflect that the pandemic is one of the plagues leading to the loss of human lives in the Democratic Republic of Congo in general, and Kinshasa in particular. Kinshasa is the second largest city in Sub-Saharan Africa, and approximately one Congolese in ten lives in the capital city. The growth of population overwhelms medical facilities, which consequently, limits the health care provided by public hospital, clinics and dispensaries. The persistent wars that know the country since the fall of Mobutu's regime in 1997, systematic pillage of natural resources, embezzlement of public funds, corruption, lack of responsible leadership and management have all converged to impoverish the population (Kabemba, 2011). Thus, in terms of Human Development Indicators (nutrition, literacy, life expectancy at birth, availability of clean drinking water, etc.) the country is amongst the poorest of the poor (World Bank, 2008). Hence it becomes relevant to examine the relationship between the people's socioeconomic status and the incidence of HIV/AIDS. The present study investigates, with regards to what have been mentioned previously, the correlation between the socioeconomic status and sexual behaviour in order to determine the existence or not of a pattern between both variables. It also examines the existence of a possible association between people socioeconomic status and their level of knowledge regarding HIV/AIDS, attitude towards HIV/AIDS, accessibility to HIV/AIDS information and availability of condoms viewed as factors that influence people's sexual behaviour. Furthermore, the study looks at the difference between the socioeconomic groups in sexual behaviour, HIV/AIDS knowledge, attitude towards HIV/AIDS, accessibility to HIV/AIDS information and availability of condoms in order to pick out the existence or not of disparities.

\section{Methodology}

Data collection: A combination of multi-stage stratification and quota was used to sample the population. Therefore, Kinshasa was first divided into four groups of suburbs, which represented the four districts of the city: Lukunga (Area 1), Funa (Area 2), Mont-Amba (Area 3) and Tshangu (Area 4). Secondly, 3 suburbs were selected from each district (areas) and a quota of 30 respondents has been applied to each suburb.

Sampling: A number of 360 (30 x 12) respondents made up the study's sample. Among them, 55.3\% were male while $44.7 \%$ were female. $64.39 \%$ of respondents have been classified as impoverished people, $9.44 \%$ as medium and $29.17 \%$ as wealthy through the use of the SAARF LSM (Living Standards Measure).

Survey instrument: The respondents have been asked to answer an open-ended survey questionnaire that measure the level in which they engage in safe sexual practices ( 6 items), their level of knowledge regarding 
the meaning of HIV/AIDS (6 items), the modes of HIV/AIDS transmission (13 items), the methods of HIV/AIDS prevention ( 9 items), and attitude towards HIV/AIDS (6 items). The accessibility to HIV/AIDS information has been assessed through 14 items that ask respondents to identify the sources that provide them with HIV/AIDS information while the availability of condoms has been measured through 5 items looking at the types of outlets providing condoms in the respondents' area. Reliability of the questionnaire has been determined using Cronbach's Aplha, relationships between variable have been tested with Pearson product moment correlation while differences between socioeconomic groups required the use of ANOVA.

\section{Findings}

The reliability of the measuring instruments determined by means of Cronbach's Alpha confirms that the questionnaire is reliable. Cronbach's Alpha of constructs from 0.716 to 0.788 . Details on what were the scores by variables are shown in table 1. It provides a summary of the scores, not by singular item but by grouping scores of items that form the variables into two categories, positive and negative. The positive category is the summation of scores that reflect the respondents' propensity to adopt safe sexual behaviour, their knowledge of respondents (3 constructs), good understanding of HIV/AIDS issues, the exposure to information and availability of condoms, safe sexual behaviour and the influence of HIV/AIDS advertising on their decision making. By contrast, the negative category is the summation of scores that highlight the respondents' propensity to engage in risky sexual behaviour, their lack of knowledge (3 constructs), poor understanding of HIV/AIDS issues, the lack of exposure to information and lack of availability of condoms.

The observations made with regard to results in table 1 are presented as follows:

- Respondents' sexual behaviour is reasonably unsafe with a score of 50.74\%;

- Respondents are reasonably knowledgeable of the meaning of HIV/AIDS with a score of 58.19\%, and highly knowledgeable of modes of HIV/AIDS transmission with a score of $73.82 \%$. They lack, however, knowledge of all the precautions to avoid contamination, with a score of $70 \%$. The results also show a good understanding of HIV/AIDS issues with a score of $83.70 \%$;

- In terms of exposure to information and availability of condoms, the results indicate a poor exposure to information promoting HIV/AIDS prevention messages, with a score of $28.29 \%$. Likewise, availability of condoms is limited, with a score of $39.28 \%$.

Table 1: Descriptive statistics of constructs measured

\begin{tabular}{llll}
\hline & Total & Positive & Negative \\
\hline Sexual behaviour & 2160 & 1064 & 1096 \\
& $100 \%$ & $49.26 \%$ & $50.74 \%$ \\
Level of knowledge about the meaning of HIV/AIDS & 2160 & 1257 & 903 \\
& $100 \%$ & $58.19 \%$ & $41.81 \%$ \\
Level of knowledge about the modes of HIV/AIDS & 4680 & 3455 & 1225 \\
transmission & $100 \%$ & $73.82 \%$ & $26.18 \%$ \\
Level of knowledge about the methods of HIV/AIDS & 3240 & 972 & 2268 \\
prevention & $100 \%$ & $30 \%$ & $70 \%$ \\
Attitudes towards HIV/AIDS (Understanding) & 2160 & 1808 & 352 \\
& $100 \%$ & $83.70 \%$ & $16.30 \%$ \\
Sources of information & 5040 & 1426 & 3614 \\
& $100 \%$ & $28.29 \%$ & $71.71 \%$ \\
Availability of condoms & 1800 & 707 & 1093 \\
& $100 \%$ & $39.28 \%$ & $60.72 \%$ \\
\hline
\end{tabular}

Results in table 2 demonstrate that no practically significant correlation was found between the people's socioeconomic status and their sexual behaviour, meaning that people's sexual practices are not associated with their socioeconomic status. Similarly, no practically significant correlation is indicated between people's socioeconomic status and their level of HIV/AIDS knowledge (all 3 constructs), implying that the socioeconomic status is not a determinant of the level of HIV/AIDS knowledge. By contrast, a practically significant positive correlation was found between people's socioeconomic status and their attitude towards HIV/AIDS ( $\mathrm{r}=.126$; small effect size; $\mathrm{p}<.05$ ), implying that people have better understanding of HIV/AIDS 
issues when they are in better socioeconomic conditions. Therefore, the socioeconomic status s determine people's attitude towards HIV/AIDS.

Table 2: Correlation between socioeconomic status, sexual behaviour, HIV/AIDS knowledge (3 variables), attitudes towards HIV/AIDS, sources of information and availability of condoms

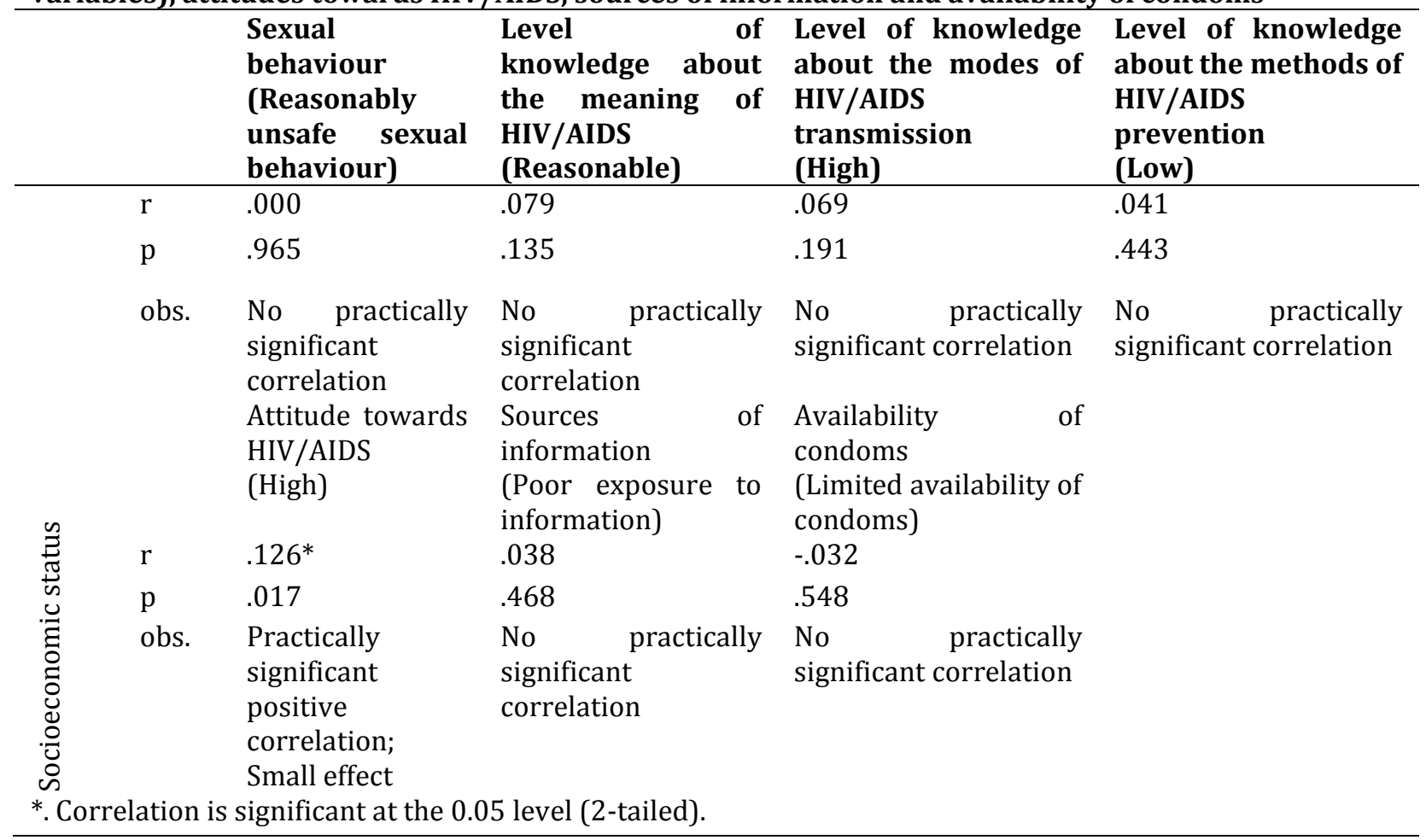

Lastly, table 2 shows no practically significant correlation between people's socioeconomic status and both the exposure to information and availability of condoms. This implies that access to HIV/AIDS information and availability of condoms does not dependent on the socioeconomic conditions of a person. Noticeably, no significant difference between the three socioeconomic groups was found in scores regarding the other variables. Therefore, the study concludes that people are all exposed to the pandemic threat no matter their socioeconomic status. In other terms, there is no socioeconomic group that should be considered as most-atrisk of infection. Results allowed also the study to argue that people are knowledgeable or not about HIV/AIDS regardless their level of precariousness or wealth. Lastly, people do not have better exposure to HIV/AIDS information or access to condoms because of to their socioeconomic conditions. Furthermore, in order to pick out disparities between socioeconomic groups, a one-way between-groups analysis of variances was conducted to explore the impact of socioeconomic status on all variables, as measured by the research instrument. Participants were divided into three groups according to their socioeconomic status (Group 1: Impoverished, Group 2: Medium and Group 3: Wealthy). Table 3 indicates that there was a statistically significant difference at the $\mathrm{p}<.05$ level in attitude towards $\operatorname{HIV} / \operatorname{AIDS}\left(\mathrm{F}_{(2,357)}=2.89 ; \mathrm{p}=.05\right)$ for the three socioeconomic groups. The Eta squared value as calculated in dividing the sum of squares between groups (70.062) and the total sum of squares (4321.469) is .02. This result indicates that despite reaching statistical significance the actual differences in mean scores between the socioeconomic groups were quite small. However at this stage, table 3 does not allow the study to identify the groups between which the mean differences in score are statistically significant in attitude towards HIV/AIDS. This is made possible through the Post Hoc Tests comparisons using the Tukey HSD highlighted in table 4. 
Table 3: ANOVA/ Socioeconomic status

\begin{tabular}{|c|c|c|c|c|}
\hline & & df & $\mathbf{F}$ & Sig. \\
\hline \multirow[t]{3}{*}{ Sexual behaviour } & Between Groups & 2 & .248 & .780 \\
\hline & Within Groups & 357 & & \\
\hline & Total & 359 & & \\
\hline \multirow{3}{*}{$\begin{array}{l}\text { Knowledge about the meaning } \\
\text { of HIV/AIDS }\end{array}$} & Between Groups & 2 & 1.136 & .322 \\
\hline & Within Groups & 357 & & \\
\hline & Total & 359 & & \\
\hline \multirow{3}{*}{$\begin{array}{l}\text { Knowledge about the modes of } \\
\text { HIV/AIDS transmission }\end{array}$} & Between Groups & 2 & .862 & .423 \\
\hline & Within Groups & 357 & & \\
\hline & Total & 359 & & \\
\hline \multirow{3}{*}{$\begin{array}{l}\text { Knowledge about } \\
\text { HIV/AIDS prevention methods }\end{array}$} & Between Groups & 2 & .433 & .649 \\
\hline & Within Groups & 357 & & \\
\hline & Total & 359 & & \\
\hline \multirow{3}{*}{$\begin{array}{l}\text { Attitudes towards } \text { HIV/AIDS } \\
\text { (Understanding of } \mathrm{HIV} / \text { AIDS } \\
\text { issues) }\end{array}$} & Between Groups & 2 & 2.894 & $.050^{*}$ \\
\hline & Within Groups & 357 & & \\
\hline & Total & 359 & & \\
\hline \multirow[t]{3}{*}{ Sources of information } & Between Groups & 2 & 1.260 & .285 \\
\hline & Within Groups & 357 & & \\
\hline & Total & 359 & & \\
\hline \multirow[t]{3}{*}{ Availability of condoms } & Between Groups & 2 & 2.476 & .086 \\
\hline & Within Groups & 357 & & \\
\hline & Total & 359 & & \\
\hline
\end{tabular}

Table 4: Multiple comparisons/ Socioeconomic status in attitude towards HIV/AIDS

Tukey HSD

\begin{tabular}{|c|c|c|c|c|c|c|}
\hline \multirow{2}{*}{$\begin{array}{l}\text { Significant } \\
\text { variables } \\
\text { mean } \\
\text { differences }\end{array}$} & \multirow[b]{2}{*}{ (I) age } & \multirow[b]{2}{*}{ (J) age } & \multirow[b]{2}{*}{$\begin{array}{l}\text { Mean } \\
\text { Difference } \\
\text { (I-J) }\end{array}$} & \multicolumn{3}{|c|}{ 95\% Confidence Interval } \\
\hline & & & & Sig. & $\begin{array}{l}\text { Lower } \\
\text { Bound }\end{array}$ & Upper Bound \\
\hline Attitude towards & $\begin{array}{l}\text { Impoverish } \\
\text { ed }\end{array}$ & Medium & -.47285 & .741 & -1.9813 & 1.0356 \\
\hline \multirow[t]{5}{*}{ HIV/AIDS } & & Wealthy & $-.98686^{*}$ & .045 & -1.9574 & -.0163 \\
\hline & Medium & $\begin{array}{l}\text { Impoverish } \\
\text { ed }\end{array}$ & .47285 & .741 & -1.0356 & 1.9813 \\
\hline & & Wealthy & -.51401 & .735 & -2.1298 & 1.1017 \\
\hline & Wealthy & $\begin{array}{l}\text { Impoverish } \\
\text { ed }\end{array}$ & $.98686^{*}$ & .045 & .0163 & 1.9574 \\
\hline & is signifi & $\begin{array}{l}\text { Medium } \\
t \text { at the } 0.051\end{array}$ & $\begin{array}{l}.51401 \\
\text { rel. }\end{array}$ & .735 & -1.1017 & 2.1298 \\
\hline
\end{tabular}


Results in table 4 indicates that there is a statistically significant difference in mean score of impoverished and wealthy people ( $\mathrm{MD}=-.98686$ ranged between -1.9574 and $-.0163, \mathrm{p}=.05$ ) in attitude towards HIV/AIDS. This means that wealthier people are more understandable of HIV/AIDS issues than their counterpart's poorer, implying that the wealthier are more likely to be less discriminative towards HIV/AIDS infected persons.

\section{Discussion and Conclusion}

The association between the socioeconomic status and magnitude of HIV/AIDS is a sensitive theme that arouses passionate debates between those who attest the existence of a correlation poverty-HIV/AIDS and those who in the contrary support that there is no pattern between both variables. Yet the two opinions are based on scientifically justified findings. In that case, what would mean to depart one another with regards to the present study findings? As highlighted in the previous section, the present study did not find an association between socioeconomic status and magnitude of HIV/AIDS. Indeed there were no correlation between people socioeconomic status and their sexual behaviour. Furthermore, though the study found a positive correlation between the socioeconomic status and attitude towards HIV/AIDS that gives an indication on people's propensity of discrimination and stigmatisation towards HIV/AIDS infected persons rather than their sexual practices, no relationship has been demonstrated between people socioeconomic status and factors that empower individuals to prevent themselves for getting infected such as HIV/AIDS knowledge, accessibility to information, and availability of condoms. Therefore, the socioeconomic status cannot be mentioned as a determinant of either sexual behaviour or HIV/AIDS knowledge or accessibility to information or availability of condoms.

The results of the analysis of variances indicate no statistically significant difference between socioeconomic groups in sexual behaviour, suggesting that no group is qualified to be considered as most-at-risk of infection. Social marketing campaigners should concentrate on all groups indistinctly. Similarly, no statistically significant difference between socioeconomic groups was found in HIV/AIDS knowledge (3 variables), implying that no group is more acknowledgeable about HIV/AIDS than another. Likewise, no statistically significant difference between socioeconomic groups was demonstrated in exposure to HIV/AIDS information and availability of condoms, meaning that there is no socioeconomic group that is better serviced by HIV/AIDS prevention interventions. By contrast, a statistically significant difference between socioeconomic groups was found in attitude towards HIV/AIDS, meaning that socioeconomic does not have the same propensity of understanding HIV/AIDS issues. Wealthier resulted to be more likely to avoid discrimination and stigmatisation towards HIV/AIDS infected people. However, despite the findings highlighted previously, it is not easy to plebiscite one mainstream to the detriment of another as being a universal truth. The authors are of the opinion that no conclusion should allow to point out one as being right and the other wrong for the simple reason that scientific truths are dependents of factors such as space and time. What is true in one region should be false in another. Also over the time truth becomes false because in this moving world change is the only static element. Therefore the study cannot embrace the view of the supporters of the inexistence of an association between socioeconomic status and magnitude of HIV/AIDS as a universal truth to the detriment of those who argue the evidence of a relationship between both variables. The findings of this study reflect the current truth of the association between socioeconomic status and magnitude of HIV/AIDS in the general population of Kinshasa. Although they are in line with the opinion of no pattern between the factors considered, it does not mean that the opposite argument is wrong if considered in a different context (space and/or time).

Acknowledgement: I would like to thank the National research foundation (NRF) in South Africa for their financial assistance to attend the 2014 IFRD conference.

\section{References}

Barnett, T. \& Whiteside, A. (2002). AIDS, Public Policy and Child Well-Being. Chapter 11: Poverty and HIV/AIDS: Impact, Coping and Mitigation Policy. UNICEF- IRC. 
Bärnighausen, T., Hosegood, V., Timaeus, I. M. \& Newell, M. L. (2007). The socioeconomic determinants of HIV incidence: evidence from a longitudinal, population-based study in rural South Africa. AIDS, 21(7), S29-S38.

Booysen, F. R. \& Summerton, J. (2002). Poverty, Risky Sexual Behaviour, and Vulnerability to HIV Infection: Evidence from South Africa. Journal of Health Population Nutrition, 20(4), 285-288.

Gillespie, S., Kadiyala S. \& Greener, R. (2007a). Is poverty or wealth driving HIV transmission? AIDS, 21(7), S5-S16.

Gillespie, S., Greener, R., Whiteside, A. \& Whitworth, J. (2007b). Investigating the empirical evidence for understanding vulnerability and the associations between poverty, HIV infection and AIDS impact. AIDS, 21(7), S1-S4.

Kabemba, K. C. (2011). Democratisation and the Political Economy of a Dysfunctional State: The Case of the Democratic Republic of Congo. Unpublished doctoral dissertation, University of Witwatersrand, Johannesburg.

Khonde, C. N. (2006). An Oral History of HIV/AIDS in the Congo. The HIV/AIDS Epidemic in Sub-Saharan Africa in a Historical Perspective. Brussels.

Lopman, B., Lewis, J., Nyamukapa, C., Mushati, P., Chandiwana, S. \& Gregson, S. (2007). HIV incidence and poverty in Manicaland, Zimbabwe: is HIV becoming a disease of the poor? AIDS, 21(7), S57-S66.

Mabala, R. (2006). From HIV prevention to HIV protection: addressing the vulnerability of girls and young women in urban areas. Environment and Urbanization, 18(2), 407-432.

Meekers, D. \& Rahaim, S. (2005). The importance of socio-economic context for social marketing models for improving reproductive health: Evidence from 555 years of program experience. BMC Public Health, $5(10)$.

Mishra, V., Assche, S. B. V., Greener, R., Vaessen, M., Hong, R., Ghys, P. D., Boerma, J. T., Assche, A. V., Khan, S. \& Rutstein, S. (2007). HIV infection does not disproportionately affect the poorer in sub-Saharan Africa. AIDS, 21(7), S17-S28.

Price, N. (2001). The performance of social marketing in reaching the poor and vulnerable in AIDS control programmes. Health Policy and Planning, 16(3), 231-239.

Slaymaker, E., Walker, N., Zaba, B. \& Collumbien, M. (2004). Comparative Quantification of Health Risks: Global and Regional Burden of Disease Attributable to Selected Major Risk Factors Volume 2. Chapter 14: Unsafe Sex. WHO, Geneva.

UNAIDS/WHO. (2004). Epidemiological Fact Sheet on HIV/AIDS and Sexually Transmitted Infections, 2004 Update.

USAID. (2008). Democratic Republic of Congo: HIV/AIDS Health Profile. Retrieved on 15 October 2011 from http://www.usaid.gov/our_work/global_health/aids/Countries/africa/congo.htm.

World Bank. (2008). Poverty data: A supplement to World Development indicators 2008. Washington, D.C. 